\title{
MARIO VARGAS LLOSA Y EL 'PECADO NEFANDO’
}

\author{
Dieter Ingenschay \\ Humboldt-Universität zu Berlin \\ dieter.ingenschay@cms.hu-berlin.de
}

\begin{abstract}
RESUMEN / ABSTRACT
En numerosos artículos y ensayos Vargas Llosa ha tomado posición a favor de los derechos de homosexuales (lo que ha provocado fuertes reacciones de ciertas personas u organizaciones homófobas). En su obra de ficción, la homosexualidad no tiene un papel muy importante, pero con la figura de Mayta, encontramos, ya en los años 1980, a un homosexual en el proceso de su emancipación. En contra de estas tendencias en su obra, el protagonista de El sueño del Celta sufre permanentemente de su 'disposición sexual' supuestamente problemática.

Palabras Clave: Vargas Llosa, derechos de homosexuales, Mayta, 'disposición sexual'.

Vargas Llosa has defended the rights of homosexuals in numerous articles and essays, a fact that has provoked strong reactions by homophobic individuals and organizations. In his fiction, homosexuality does not play an important role, but in the figure of Mayta we find, as early as in the 1980s, a homosexual in the process of emancipation. Against these trends in his work, the protagonist of $\mathrm{El}$ sueño del Celta suffers permanently from his supposedly problematic "sexual disposition".
\end{abstract}

KEY WORDS: Vargas Llosa, rights of homosexuals, Mayta, "sexual disposition".

\section{INTRODUCCIÓN: VARGAS LLOSA PERIODISTA Y LA CUESTIÓN DE LA 'EMANCIPACIÓN HOMOSEXUAL'}

Tras la publicación de El sueño del celta de Mario Vargas Llosa se ha reactivado la discusión sobre la posición del Premio Nobel frente a la homosexualidad, ya que sitúa a Roger Casement, un protagonista homosexual, en el centro de 
esta novela de fuerte carga biográfica. Hasta ahora ha sido escasa la crítica literaria sobre las diferentes formas de vida homosexual en la obra del autor peruano, más bien ocupan un rol central las conocidas configuraciones heterosexuales, de forma ejemplar en las dos novelas eróticas Elogio de la madrastra y Los cuadernos de Don Rigoberto. Sin embargo el diccionario online sobre temática homosexual en la literatura latinoamericana informa de algunos arabescos homosexuales en Vargas Llosa: en tres de sus obras de teatro aparece temática homosexual, no tan explícita en la novela Conversación en la catedral. También se puede agregar El paraíso en otra esquina, si subsumimos aquí la transgresiva sexualidad de Paul Gauguin. Cuando el pintor arribó a Tahiti en 1891 con la melena ondeando al viento y un cuello de piel de color roja, fue identificado por los Papeete como un "mahu", representante del género de Hombre-Mujer que había existido durante cientos de años en la cultura maorí, pero que fue erradicado mediante la adoctrinación de los misionarios católicos y protestantes. Además de estas novelas -tomando en cuenta la interpretación que hace Ben Sifuentes Jáuregui ${ }^{1}$ - podemos añadir a otro protagonista con connotaciones homosexuales, el personaje de Cuellar en Los cachorros, que sufre una castración provocada por el mordisco de un perro y que se caracteriza después por su ablandamiento y afeminización.

Más tarde volveré a la novela Historia de Mayta, donde Vargas Llosa trata el tema de manera más intensa, también a El sueño del celta. En primer lugar, propongo enfocar el Vargas Llosa ensayista (o periodista), que se ha expresado en algunos artículos escritos en las últimas décadas sobre el proceso de la 'emancipación homosexual'. En ellos se centran sus manifestaciones -de manera paralela a favor del aborto o del divorcio- en contra de las posiciones más dogmáticas conservadoras (que, por regla general, pertenecen a los círculos religiosos fundamentalistas). Me refiero de manera particular a los artículos "Contacto visual" y "Cruzados del arco iris", publicados en su libro Desafios a la libertad, así como a los articulos periodísticos "El pintor en el burdel", "El pecado nefando", "El matrimonio gay" y "Los hombresmujeres del Pacífico".

${ }^{1}$ Es la interpretación expuesta en Sifuentes Jáuregui, Ben. Transvestism, masculinity, and Latin American literature: genders share flesh. Me refiero sobre todo a una ponencia leída por Sifuentes en Dartmouth College en julio de 2010 que forma parte de un libro en vía de publicación. 
En 2003, cuando Karol Woytila todavía regía sobre el Vaticano y su rebaño, publicó nuestro autor en el diario argentino La Nación un artículo con el título "El pecado nefando".

En él comentaba la posición tomada por el Vaticano acerca (o más bien: en contra) de un 'matrimonio gay' o una vida en común de personas del mismo sexo, redactada por el entonces Prefecto de la Congregación para la Doctrina de la Fe, Joseph Ratzinger. Vargas Llosa no se sorprende tanto por el requerimiento que hicieron aquí a los políticos de ponerse de manera masiva en contra de las nuevas libertades, sino por el fuerte tono y la estrategia argumentativa utilizada por el Gran Inquisidor en funciones. Vargas Llosa subraya especialmente la invectiva del cardenal, entretanto ascendido a la sede del presunto Santo Padre, contra el derecho de adopción de parejas del mismo sexo, porque esta forma de vida en contra de "la ley natural moral" podría influir negativamente en la vida y la formación de los jóvenes. Vargas Llosa da un fuerte golpe en la mesa contra esa posición, fundamentándose en afilados argumentos históricos (en su mayoría conocidos):

Con argumentos así, aderezados con la presencia sulfúrica del demonio, la Iglesia mandó a millares de católicos y de infieles a la hoguera en la Edad Media y contribuyó decisivamente a que, hasta nuestros días, el alto porcentaje de seres humanos de vocación homosexual viviera en la catacumba de la vergüenza y el oprobio, fuera discriminado y ridiculizado y se impusiera en la sociedad y en la cultura el machismo, con sus degenerantes consecuencias: la postergación y humillación sistemática de la mujer, la entronización de la viril brutalidad como valor supremo y las peores distorsiones y represiones de la vida sexual en nombre de una supuesta normalidad representada por el heterosexualismo.

Parece increíble que después de Freud y de todo lo que la ciencia ha ido revelando al mundo en materia de sexualidad en el último siglo la Iglesia Católica [...] se empecine en una doctrina homofóbica tan anacrónica como la expuesta en las doce páginas redactadas por el cardenal Joseph Ratzinger (Vargas Llosa, "Pecado").

Estas no son ni de lejos las únicas palabras claras con las que el novelista peruano condena la funesta homofobia de la Iglesia Católica, lo cual le ha llevado a ganarse la enemistad de gran número de fundamentalistas católicos y partisanos del Opus Dei (la mayoría operando desde internet). Entre ellos sobresale un tal René Flores Agreda, que en las publicaciones previas de su 
libro en proyecto sobre (o contra) Vargas Llosa, le acusa de moverse en un terreno nada científico, ya que después de todo está demostrado 'científicamente' que la homosexualidad es curable ("Basta referirse a la exitosa terapia de la desviación de la orientación sexual, confirmada hace poco por el gurú de la psiquiatría americana Spitzer"). Flores Agreda sigue, contra viento y marea, apoyando la posición ridícula y objetivamente falsa de que la homosexualidad es una enfermedad, una desviación. Además, el término homofobia utilizado por el autor peruano sería, según Flores Agreda, una mera invención de la comunidad gay (Flores, "Homosexualidad").

En el artículo "El matrimonio gay", publicado en El País el 26 de junio de 2005, cuando la discusión sobre la consolidación de las parejas de hecho causaba sensación en España, acometió Vargas Llosa con un encendido alegato a favor de los partidarios del matrimonio homosexual. También a este artículo se produjo como era de esperar la réplica del pseudocientífico católico Flores Agreda:

Baste señalar que mezcla normalidad con enfermedad, no distingue las variantes en estos diferentes ámbitos, hace afirmaciones sin mayor sustento -como en el caso de la adopción de niños por personas con homosexualidad- y no se da por enterado del uso cuestionable del término 'opción' (Flores, "Homosexualidad").

Vargas Llosa no se limita solamente a atacar las conocidas posiciones homófobas de las Iglesias, sino que se distancia por su comportamiento sobre el tema del Partido Popular español, al cual algunos le habían situado en su entorno político.

Como liberal creo que medidas como la despenalización del aborto, los matrimonios gays y el derecho de las parejas homosexuales a adoptar niños son medidas de progreso que aumentan la libertad y los derechos humanos en España, y por tanto, no me puedo sentir representado por un partido que rechaza esas reformas (Vargas Llosa, "El matrimonio").

Lo que me interesa de la misma manera es exponer la típica opinión 'liberal' del último Premio Nobel y la terquedad de un grupo de población no tan pequeño. Apenas menos curioso es recordar las especulaciones acerca de una eventual expulsión de Vargas Llosa del Colegio Militar Leoncio Prado en 1950/1951 por actividades homosexuales, como cree haber conseguido filtrar una plataforma de internet de conversaciones con compañeros de su clase. 
Que lo que él plasmó en La ciudad y los perros fue una manera de digerir psicológicamente sus experiencias de la academía de cadetes, también lo cree Birger Angvik ${ }^{2}$. Otra nueva variante que se ha planteado recientemente fue cuando una profesora que trabaja en una universidad norteamericana, al conocerse el premio Nobel, en lugar de escribirle a Vargas Llosa una carta de felicitación, se la envió a su ex-mujer, a la 'tía Julia' de la conocida novela. En esta "carta a Julia" exponía que nuestro autor solo desarrolló su interés por temas mal vistos como oposición al homófobo de su padre, y por ello se convirtió en escritor. Enhorabuena. De todas formas, ningún comentario serio atribuye a nuestro autor realmente un deseo homosexual, o que éste haya sido reprimido. Vamos a enfocar ahora sus propios textos de ficción.

\section{2. "TU NO ERES HOMBRE, MAYTA". LA CONSTRUCCIÓN SOCIAL DE LA HOMOFOBIA: HISTORIA DE MAYTA}

Historia de Mayta, publicada en 1984, es más que nada una metanovela que se deja leer maravillosamente como ilustración de la teoría vargasllosiana de la novela como verdad de las mentiras, en la cual la propia historia se cuestiona una y otra vez y se la presenta explícitamente como una mentira. De manera explícita, el autor-narrador de Historia de Mayta se manifiesta cuando postula, al igual que el Vargas Llosa teórico y crítico: "porque soy realista, en mis novelas trato siempre de mentir con conocimiento de causa" (Vargas Llosa, Historia 77). Esto vale también para el tema relevante en el contexto dado: la homosexualidad de Mayta. A continuación me gustaría explicar este punto más detenidamente. En Historia de Mayta, Vargas Llosa utiliza una variante específica de su modelo de los vasos comunicantes, en este caso el invisible paso entre el presente de las investigaciones del narrador (que no es idéntico al presente de la narración - esto es, las conversaciones con sus informadores) y el añadido de elementos pseudodocumentales en la trama. Estos elementos añadidos sirven para reconstruir el pasado, la mayoría de las veces en forma de escenas o encuentros de los personajes con Mayta.

Desde el principio de la novela, una alusión poco sutil nos remite a la posible homosexualidad de Mayta, el negarse a bailar con mujeres (Vargas

2 Me refiero a Angvik, Birger: La narración como exorcismo. Mario Vargas Llosa, obras (1963-2003). En la página 22 está la referencia. 
Llosa, Historia 25). Cuando Mayta conoce al interesante y atractivo alférez Vallejitos, se imagina qué tipo de mujer le podría haber besado, lo que corresponde a una típica triangulización del deseo en el sentido de René Girard. De golpe revienta el deseo homosexual cuando Mayta, en el contexto homosocial de la milicia revolucionaria, no puede contener su deseo, y se fija en el miliciano Anatolio que está tumbado en la cama junto a él:

Su cara estaba muy cerca del hombro desnudo del muchacho. Un olor a piel humana, fuerte, elemental, se le metió por la nariz y lo mareó. Sus rodillas, encogidas, rozaban la pierna de Anatolio. (...) Despacio, estiró su húmeda mano derecha que temblaba y, palpando, llegó a su pantalón:

- Déjame corrértela -murmuró, con voz agonizante, sintiendo que todo su cuerpo ardía - Déjame, Anatolio (Vargas Llosa, Historia 108).

Poco después de esta escena cambia la narración al nivel de la audición de los testigos, y el senador Campos pregunta al narrador: "Usted sabe que Mayta era invertido, por supuesto" (108). A la observación del narrador si esto sería de importancia en el resultado del intento de revolución de Jauja, el senador (que fue en sus tiempos uno de los revolucionarios) responde con una cadena de reflexiones acerca de la homosexualidad en Latinoamérica y en los países socialistas que seguramente no era atípica en el contexto sudamericano de los años 1980.

¿Se puede tener confianza en un homosexual? Un ser incompleto, feminoide, está hecho a todas las flaquezas, incluida la traición. (...) ¿Por qué ... no existen casi homosexuales en los paises socialistas? (...) Porque hay en esas sociedades mucho que imitar. En ellas ha desaparecido la cultura del ocio, el vacío anímico, esa inseguridad existencial típica de la burguesía que duda incluso del sexo con el que ha nacido. Maricón es indefinición, valga el pareado" (109).

Un posible mensaje de la novela puede ser la constatación de que los grupos revolucionarios también permanecen en su obstinada homofobia que se encuentra, por ejemplo, en la posición de la revolución cubana con su concepto machista del 'hombre nuevo'. La narración continúa con el hilo argumental de Mayta y Anatolio. Cuando el joven, indignado, rechaza el deseo de Mayta, y le mata simbólicamente ("Para mí has muerto esta noche", 113), y quiere delatarle al partido. Habiendo tomado el senador otra vez la palabra, se derrumba el bastión heteronormativo cinco páginas más tarde: 
Anatolio, acometido por un deseo espontáneo, acepta parcialmente: "Puedes corrérmela, si quieres -lo oyó susurrar, con timidez (...)- pero nada más que eso, Mayta" (118).

Después de que Mayta informase a un comunista fiel a Moscú acerca de la inminente acción revolucionaria, será juzgado por su grupo trotsquista, permaneciendo los prejuicios en contra de los homosexuales dentro de la izquierda política, cuando le reprocha, esta vez el camarada Joaquín, que él no es un hombre ("tú no eres un hombre, Mayta", 180), por haber estado en contacto con el enemigo ("Esa manera de proceder, tortuosa, caprichosa, eso de ir a buscar a nuestro enemigo, es feminoide, camaradas. [...] ¿Se puede ser un revolucionario leal y un invertido? Esa es la madre del cordero, camaradas", 181). Adelaida, la mujer de Mayta (en el nivel de la historia reconstruida) quiere convencer una y otra vez a su marido para que se someta a una terapia de electrochoques, lo que provoca una reacción que podría garantizar a Mayta una plaza de honor en el Panteón de protagonistas del movimiento homosexual: "No fue por miedo -dijo, bajito, mirándola. Fue porque no quería curarme" (217), y a continuación:

Quiero ser el que soy -tartamudeé- . Soy revolucionario, tengo pies planos. Soy también maricón. No quiero dejar de serlo. Es difícil explicártelo. En esta sociedad hay unas reglas, unos prejuicios, y todo lo que no se ajusta a ellos parece anormal, un delito o una enfermedad. Pero es que la sociedad está podrida (218).

De esta manera, Mayta articula lo que en el movimiento homosexual alemán el director de cine berlinés Rosa vom Praunheim sostuvo en su documental programático Nicht der Homosexuelle ist pervers, sondern die Situation, in der er lebt (1970) (Perversa no es la persona homosexual sino la situación en la que vive). Los pocos autores que reflexionan sobre la temática homosexual en Historia de Mayta, han olvidado, o pasado por alto, que ese mismo Mayta, al encontrarse con el narrador después de una larga estancia en la cárcel, es un hombre casado con hijos que muestra su rechazo a los homosexuales, y no sabemos dónde reside la verdad entre todas estas mentiras.

¿Qué verdad se esconde tras la mentira del Mayta homosexual? Hay que recordar que en el año 1984 el trotsquista Mayta no debía despertar mucha simpatía en nuestro novelista liberal. El homosexual no es solo el paradigma de los marginados y los perseguidos, al que se dirigen las sospechas y prejuicios de la sociedad machista latinoamericana de los 80 , como décadas después la Iglesia Católica vuelve a probarlo en el panfleto mencionado del cardenal 
Ratzinger. El Mayta homosexual es una figura literaria que incorpora 'verdad' porque la sociedad le atribuye este tipo de roles. La construcción social del homosexual, que Foucault describe y localiza en el siglo XIX, es también aquí el tema de Vargas Llosa. A la 'verdad' de la novela, en la que Mayta puede desarrollar su modesta autoconfianza gay, se opone la 'mentira' socialmente construida que convierte al homosexual en chivo expiatorio. En este proceso, Mayta no es simplemente un héroe positivo, sino una personalidad compleja, idealista que podría ser ejemplar por la aceptación de su orientación sexual, a pesar del fracaso de su misión. Que el Mayta recobrado al final no sea homosexual, que no mencione los años de colegio vividos juntos, destaca el carácter construido de los personajes.

\section{EL "LADO OSCURO” DE LA SEXUALIDAD INDIVIDUAL: $E L$ SUEÑO DEL CELTA}

La nueva obra de Vargas Llosa es claramente biográfica, a diferencia de Historia de Mayta. Los tres grandes proyectos del protagonista, Roger Casement, nacido en 1984 en Irlanda y ejecutado por traición en 1916 en Londres, son todos históricos en un sentido convencional, es decir, garantizados por la historia real de los hechos. Estos proyectos son los siguientes: primero, la misión, por encargo del gobierno británico, de investigar los “delitos contra la Humanidad" - diciéndolo de manera actual- que están practicando los poderes coloniales en el Congo Belga. El segundo encargo de Casement es, en la región fronteriza entre Perú, Colombia y Brasil, investigar el inimaginable y cruel maltrato y asesinato de los pueblos indígenas, que están a cuenta del peruano Julio César Arana, director de la Peruvian Amazon Company, registrada en la bolsa londinense. El tercer proyecto de este funcionario de alto rango del gobierno británico tiene otra naturaleza: el redescubrimiento de sus raíces irlandesas, que le lleva al paulatino equiparamiento de las víctimas del colonialismo en África y América con la ocupación de Irlanda por parte del Imperio. Mientras que su entusiasta participación en las dos primeras misiones se puede considerar ejemplar, desde la perspectiva del presente postcolonial, el protagonista se descalifica a sí mismo a consecuencia de su ceguera nacionalista, que le lleva a colaborar con Alemania, enemigo de Gran Bretaña en la Primera Guerra Mundial. Su compromiso patriótico implica la traición de su primer patrono, y ello finalmente conlleva su acusación y ejecución. Vargas Llosa, enemigo claro de conceptos nacionalistas o 
patrióticos, pone así en boca de George Bernhard Shaw la siguiente crítica al nacionalismo de Casement: "el patrotismo es una religión, está reñido con la lucidez. Es puro oscurantismo, un acto de fe" (Vargas Llosa, El sueño 197).

La homosexualidad de Casement se pone de manifiesto, como en el caso ya aclarado de Mayta, cuando se habla de mujeres (45), una circunstancia que apenas puede ser un "documento histórico". En el caso de la novela 'histórica' sobre Trujillo, con la tematización del deseo pedófilo-heterosexual del dictador, algunos de sus "defensores" habían confirmado que esto de hecho correspondía a la 'verdad histórica' demostrable. El principal reproche que le hacen a Vargas Llosa es en relación a como maneja, en La fiesta del chivo, los datos históricos y, sobre todo, que no haya aclarado qué elementos históricos había tomado de la obra del historiador Bernard Diederich, Trujillo. The Death of the Goat (1978). Para que esto no se repita en el caso de Casement, nuestro autor buscó desde el principio el contacto con el determinante biógrafo de Casement, Angus Mitchell, y publicó un dialogo con él sobre la dimensión histórica de su novela ${ }^{3}$.

En este diálogo se habla también sobre la homosexualidad de Casement, al igual que en la novela, cuando ya en las primeras páginas, mientras Casement espera en la cárcel a que se lleve a cabo su ejecución, se entera por medio de un guardián de que Scotland Yard ha encontrado sus diarios. A esta altura, el lector no sabe todavía que, como saldrá a la luz en el trascurso de la novela, este diario aparece solo en el contexto de las experiencias homosexuales que Casement anota en él en frases cortas, de estilo telegráfico. Un ejemplo: "Muy hermoso y enorme. Lo seguí y lo convencí. Nos besamos ocultos por los helechos gigantes de un descampado. Fue mío, fui suyo, Aullé” (113).

Esta frase esta precedida por una escena en la que el protagonista, nada más llegar a Luanda, observa a un grupo de africanos con poca ropa encima que descargan sacos de algodón.

Uno de ellos, el más joven, era muy hermoso. Tenía un cuerpo alargado y atlético, músculos que asomaban en su espalda [...]. Su piel oscura, algo azulada, brillaba de sudor. Con los movimientos que hacía al desplazarse con la carga al hombro ..., el ligero pedazo de

${ }^{3}$ Hago alusión a Mitchell, Angus, “An interview with Mario Vargas Llosa' and the Irish-Argentine Dimension”. También en red (www.irlandeses.org/imsla0907.htm), última consulta 12 de junio de 2011. 
tela que llevaba envuelto en la cadera se abría y dejaba entrever su sexo, rojizo y colgante y más grande que lo normal (113).

El lector podría presumir aquí que el diario describe lo que el informe calla. Pero no es así; según avanza la lectura, se verá cada vez más claro que el registro del diario es de otra categoría, porque estas entradas resultan ser productos de su fantasía, y no reflejos de lo ocurrido. De manera explícita a mitad de la novela se puede leer:

Una tarde, en que luchaba contra la sensación de impotencia que lo vencía, fantaseó así en su diario: 'Tres amantes en una noche, dos marineros entre ellos. ¡Me lo hicieron seis veces! Llegué al hotel caminando con las piernas abiertas como una parturienta'. En medio de su mal humor, la enormidad que había escrito le provocó un ataque de risa (303).

Concluimos que lo que provoca la risa del protagonista es su propia fantasía y no un hecho vivido. Después de recibir en Las Palmas en las Islas Canarias, un navajazo no muy serio pero si doloroso, tras haberle hecho una clara proposición a un chaval, leemos:
A la mañana siguiente, mientras desayunaba, abrió su diario y, escribiendo despacio y con letra apretada, hizo el amor con Miguel, varias veces, primero en la oscuridad del parque Santa Catalina oyendo el murmullo del mar, y, luego, en el cuarto pestilente de un hotelito desde el que se oían ulular las sirenas de los barcos. El muchacho moreno cabalgaba sobre él, burlándose, 'eres un viejo, eso es lo que eres, un viejo viejísimo', y dándole unos manotazos en las nalgas que lo hacían gemir, acaso de dolor, acaso de placer (380).

Vargas Llosa ha aclarado, en la mencionada entrevista con el historiador Mitchell, que no quería desgastar demasiado el diario. Bien es verdad, dice el escritor, que Casement fuera indiscutiblemente homosexual, pero no se puede documentar al cien por cien la autenticidad de los Black diaries. En definitiva, podría tratarse de una falsificación del servicio secreto británico, con el cual le pudieran incriminar al colaborador y poner a la opinión pública en su contra.

Pues bien, Vargas Llosa -remitiéndonos a textos como Elogio de la madrastra y a Don Rigoberto- tiene suficiente experiencia con diferentes mundos de representación (hetero-)sexuales como para poder exponer realmente 
la discrepancia entre práctica y fantasía sexual como algo específicamente homosexual. Sin embargo, es un hecho que este camino particular de superar la frustación se desarrolla en un protagonista homosexual. En la ya citada entrevista, el mismo Vargas Llosa que intercede tan explícitamente a favor de la emancipación homosexual se aferra apodícticamente a la idea de la homosexualidad de Casement como aspecto negativo: "But I think he was a homosexual. This is another very dramatic, tragic aspect of his life if you place homosexuality in the context of the prejudices and persecution of homosexuals" y poco después añade: "The homosexuality was something which was another very personal element of the tragedy he lived all his life" (Mitchell, "Interview"). Para el autor peruano, esta tragedia se plasma en el supuesto aislamiento homosexual, el cual sufre, a pesar de su anhelo de protección y amor, de una fuerza incesante de un deseo prepotente. Así la duda y el luto se apoderan una y otra vez del pobre homosexual frente a su propia forma de vida, como en el ejemplo de una escena localizada en el permisivo Brasil:

Esa noche, en el largo desvelo de su cama del Hotel do Comércio, Roger cayó en una de esas depresiones que lo habían acompañado casi toda su vida, sobre todo luego de un día o una racha de encuentros sexuales callejeros. Lo entristecía saber que nunca tendría un hogar [...]. Pagaba caro estos minutos de placer mercenario. Se moriría sin haber saboreado esa intimidad cálida, una esposa con quien comentar las ocurrencias del día y planear el futuro... (El sueño 301).

Sin embargo, el sexo pagado no es un fenémeno exclusivo ni tampoco principalmente homosexual, y en el entorno contemporáneo a Casement había ya formas de gozo de las prácticas homosexuales (y de ponerlas en el discurso literario), baste recordar las narraciones sobre Oscar Wilde y Bosy en África del Norte, como nos lo transmitió Gide en su relato autobiográfico Si ne grain ne meurt. Por supuesto, Vargas Llosa sabe todo esto, sobre todo cuando describe prostitución, violación y humillación de la mujer por el hombre en los territorios coloniales del Congo y del Amazonas como fenómenos comunes en estos días. Nos queda pues la duda, de por qué no admite a su protagonista sus fantasías sexuales y su textualización en los Black Diaries, que un psicólogo probablemente reconocería como una buena medida terapeútica. ¿Por qué se habla, al nivel extradiegético del epílogo, de "obscenidades pestilentes"? No tengo otra respuesta que ésta, ya que Vargas Llosa conoce en sus ensayos críticos las dimensiones y el significado de las 
diferentes formas de vida homosexuales, pero la prática concreta le es tan ajena que prefiere recurrir en su ficción a un curioso concepto heteronormativo de "conciencia". Con esto nos provee - a diferencia de la autodefinición decididamente homosexual de Mayta- la radiografía de un infeliz, cuya desgracia resulta de (como se decía antigüamente) una "predisposición sexual", así como si no existieran millones de heterosexuales cohibidos y reprimidos, así como si fuera la heterosexualidad una buena y la homosexualidad una mala opción, una "condena" (407).

En este sentido, la nueva novela de Vargas Llosa no solo contiene un concepto esencialista de la sexualidad, sino que refuerza también los prejuicios contra las formas de vida homosexual y retrocede con ello más allá de lo que el autor había esperado de la revolución o liberación sexual y de los movimientos post 68 y que llevaba a cuestas en el discurso de Historia de Mayta. En lugar de las tramas sensuales y llenas de humor de la vida heterosexual en sus novelas eróticas, ha retratado en El sueño del celta a un homosexual triste, perverso y cohibido que, a pesar de su admirable compromiso anticolonial, es un pobre diablo, que fracasa en todos sus anhelos personales, al que solo le queda como única salida el camino de los místicos cristianos y la disputa con la Imitatio Christi de Tomás a Kempis. Su Santidad el Papa estará contento esta vez.

Sin embargo, no quiero callar que se encuentran en El sueño del celta descripciones maestras de la mirada del deseo (ya cité arriba algunos pasajes). También tiene Vargas Llosa toda la razón cuando asegura en la entrevista ya citada con el historiador Michell, que por supuesto puede un escritor nohomosexual escribir la historia de Casement, y lo prueba el mismo texto de Vargas Llosa con sus sugestivos pasajes de gran sutileza. Por último, cabe mencionar que Vargas Llosa consigue con El sueño del celta adherirse a su tradición "peruana", a lo que ya se había dado a entender detrás de la superficie experimental de la La casa verde. A través de algunas referencias intertextuales remite a una novela latinoamericana de graves consecuencias, a La vorágine de José Eustasio Rivera (en la cual ya fueron tratadas las maquinaciones de Julio Arana, en gran parte situándolos en los mismos lugares geográficos).

Así termina la segunda parte de El sueño del Celta, "Amazonia", con una frase que retoma y radicaliza el proverbial final de La vorágine: "En un futuro muy lejano toda huella humana habría sido borrada por la selva" (339). Este tono darwinista no corresponde a la posición del ensayista ilustrado Vargas Llosa que opta por visiones positivas y toma posición en favor de la sexualidad como derecho humano, a pesar de la homofobia implícita que determina su última novela. 


\section{BIBLIOGRAFÍA}

Angvik, Birger. La narración como exorcismo. Mario Vargas Llosa, obras (1963-2003). Lima: Fondo de Cultura Económica del Perú, 2004.

Diederich, Bernard. Trujillo. The Death of the Goat. London: The Bodley Head, 1978.

Flores Agreda, René. "El Paraíso en la otra esquina y el amor en ninguna parte". Letralia $\mathrm{X} / 140$ (2006). En http://www.letralia.com/140/ensayo03.htm

Flores Agreda, René. "Homosexualidad: visión vargasllosiana”. Letralia XV/ 240 (2010). En http://www.letralia.com/240/especial204.htm

Girard, René. Deceit, Desire and the Novel. Self and Other in Literary Structure. Johns Hopkins University Press, 1965.

Foucault, Michel. Historia de la sexualidad. 1, La voluntad de saber. México, D.F./Buenos Aires: Siglo XXI, 2005.

Mitchell, Angus. "An interview with Mario Vargas Llosa and the Irish-Argentine Dimension". Irish Migration Studies in Latin America 7/2 (2009): 137-144. www.irlandeses.org/ imsla0907.htm

Sifuentes Jáuregui, Ben. Transvestism, masculinity, and Latin American literature: genders share flesh. New York: Palgrave, 2002.

Vargas Llosa, Mario. Desafios a la libertad. Lima: Peisa, 1994.

"El pecado nefando". La Nación (Buenos Aires) del 17 de agosto de 2003. En http://www.sindioses.org/sociedad/nefando.html

"El matrimonio gay". El País del 26 de junio de 2005. En http://www.elpais.com/ articulo/opinion/matrimonio/gay/elpporopi/20050626elpepiopi_7/Tes

Historia de Mayta. Barcelona: Ed. Seix Barral, 1984.

El sueño del celta. Madrid: Santillana, 2010. 